\title{
A REPRESENTAÇÃO DO CRIME DE RACISMO NO DISCURSO DO JORNAL BAIANO CORREIO
}

(The representation of the crime of racism in the speech of the Bahia newspaper Correio)

\author{
Daniele de Oliveira ${ }^{1}$ \\ (Universidade Federal da Bahia - UFBA)
}

\section{RESUMO}

Como o crime de racismo é reconfigurado na mídia online? Para responder a essa pergunta, analisei 54 manchetes de notícias sobre o crime de racismo publicadas no jornal baiano Correio no ano de 2016, sob o viés da Análise Crítica do Discurso. As categorias analíticas utilizadas foram a intertextualidade e a representação de atores sociais que mostraram como um crime pode se tornar um espetáculo quando o jornal tem como objetivo antes seduzir do que informar seu leitor. É a concretização da sociedade do espetáculo preconizada por Guy Debord em 1962.

Palavras-chave: Ator Social. Discurso Midiático Online. Intertextualidade. Racismo.

\begin{abstract}
How is the crime of racism reconfigured in the online media? To answer this question, I analyzed 54 news headlines on the crime of racism published in the Bahia newspaper Correio in the year of 2016, under the bias of Critical Discourse Analysis. The analytical categories used were the intertextuality and the representation of social actors who showed how a crime can become a spectacle when the newspaper aims to seduce rather than inform its reader. It is the concretization of the society of the spectacle advocated by Guy Debord in 1962.
\end{abstract}

Keywords: Social Actor. Online Media Speech. Intertextuality. Racism.

Recebido em: janeiro 2018

Aceito em: abril 2018

DOI: $10.26512 /$ les.v19i2.16877

\section{INTRODUÇÃO}

A sociedade contemporânea gira em torno do espetáculo. Atualmente, a mídia, independentemente do assunto tratado, tem como objetivo central seduzir o leitor e não mais, necessariamente, informar. Com isso, corrupção e crimes violentos, por exemplo, tendem a ser espetacularizados, para usarmos o termo de Debord (2017 [1992]). No que se refere ao crime de

\footnotetext{
${ }^{1}$ Professora Adjunta do Departamento de Letras Vernáculas da Universidade Federal da Bahia. Docente do Programa de Pós-Graduação em Língua e Cultura do Instituto de Letras da UFBA. Dedica-se à Análise Crítica do Discurso com foco no discurso da mídia. E-mail: danieleoliveira@yahoo.com.
} 
racismo, nota-se também uma banalização, ou seja, muitas vezes o crime é tratado no discurso jornalístico como mais uma notícia rotineira ou mais uma curiosidade sobre celebridades.

Diante desse cenário, neste trabalho, a proposta é discutir como o crime de racismo é representado no discurso do jornal baiano Correio, que circula na cidade mais negra do Brasil, Salvador. O foco da análise será em algumas das estratégias discursivas utilizadas para recontextualizar o crime nesse discurso, a saber, a intertextualidade e a representação de atores sociais.

Para alcançar esse objetivo, o corpus selecionado é composto pelas 54 notícias sobre o crime de racismo, publicadas no ano de 2016, no portal online do jornal Correio. A análise, neste trabalho, considerou apenas as manchetes dessas notícias, tendo em vista a centralidade dessa parte do texto no discurso jornalístico, muitas vezes a única considerada pelo leitor.

A discussão está subdividida em três etapas. Em primeiro lugar, mostro como o discurso jornalístico contemporâneo foi espetacularizado, em detrimento de seu caráter originalmente informativo. Para tanto, lanço mão dos conceitos de jornalismo de INFOtenimento (CASTELLS, 1999; DEJAVITE, 2007); notícia light (DEJAVITE, 2007); além de retomar a concepção de jornalismo sensacionalista, proposta por Agrimani (1995). Na sequência, apresento as categorias analíticas utilizadas para a análise, tendo em vista o viés da Análise Crítica do Discurso. A discussão gira em torno dos conceitos de intertextualidade, à luz da proposta de Fairclough (2003), e da descrição sociossemântica apresentada por van Leeuwen (2008 [1996]) por meio da qual é possível representar um ator social em determinado discurso. A terceira etapa se constitui da análise propriamente dita das manchetes das notícias que compõe o corpus, precedida de uma análise da distribuição dessas notícias nas seções do jornal. Por fim, teço algumas considerações sobre o que tal reflexão e análise sugerem sobre a prática discursiva do jornal Correio no que se refere a recontextualização do crime de racismo.

\section{A NOTí́CIA COMO ESPETÁCULO}

Já em 1962, Jürgen Habermas apontava a integração entre conteúdo informativo e entretenimento no discurso jornalístico. Para o filósofo (2003 [1962]), as pessoas se interessam mais por informações que entretém, "as tomadas de posição da redação cedem espaço às informações das agências noticiosas e às reportagens dos correspondentes; o raciocínio desaparece por trás do véu das decisões tomadas internamente sobre a seleção e a apresentação do material” (HABERMAS, (2003 [1962] p. 200-201). Dito de outra forma, ele ressalta o crescente interesse em conteúdo para consumo imediato em detrimento do interesse por informação real, o objetivo do leitor agora é sua distração e 
não o uso da razão. Ressalte-se que, a despeito da atualidade da colocação de Habermas, tal afirmação foi feita/publicada em 1962.

Na mesma década, Guy Debord publicou A sociedade do espetáculo (1967), no qual apontou que a sociedade contemporânea fez uma opção pelo consumo de assuntos que a choquem, tais como crimes e escândalos. "O espetáculo é o momento em que a mercadoria ocupou totalmente a vida social" (DEBORD, 2017 [1992], grifo do autor), fazendo, dessa forma, uma crítica ácida à sociedade do consumo contemporânea também nos anos 1960.

O que Debord e Habermas preconizaram nos anos de 1960 é uma prática jornalística que vem se tornando cada vez mais comum, qual seja, a de informar e entreter ao mesmo tempo. Atualmente, o jornalismo é mais uma opção de entretenimento do que uma fonte de informação uma vez que também tem como objetivo seduzir e descontrair. De acordo com Bucci (2000), o foco do jornalismo contemporâneo não é mais informar, mas seduzir, tudo converge para o espetáculo. Trata-se do jornalismo de INFOtenimento (CASTELLS, 1999; DEJAVITE, 2007).

Para Dejavite (2007, p. 2), “o jornalismo de INFOtenimento é o espaço destinado às matérias que visam informar e entreter, como, por exemplo, os assuntos sobre estilo de vida, as fofocas e as notícias de interesse humano (...) [o jornalismo de INFOtenimento] manifesta aquele conteúdo que informa com diversão". No entanto, ressalta a autora, o caráter híbrido desse conceito esbarra na contraposição entre o que se considera conteúdo sério e o que se considera conteúdo não sério dentro do jornalismo. Na prática, o que é considerado conteúdo sério pode ser tratado como conteúdo não sério. Citamos como exemplo o tratamento dispensado às notícias sobre o crime de racismo, tal como apresentadas pelo jornal baiano Correio, como vou mostrar mais adiante.

Dejavite (2007) aponta ainda a transformação na maneira de se fazer notícia, uma vez que atualmente há que se atender, primordialmente, à demanda do público, cada vez mais envolvido nas deliberações sobre o conteúdo a ser publicado pela mídia. O público quer informação e também distração, ou seja, agora, a notícia tem que ser light. Uma notícia pode ser considerada light quando é efêmera, circula rapidamente, apresenta novos dados, e também distrai ou agrada o leitor.

E se há que distrair o leitor, faz-se necessário contar histórias sobre personagens que o entretenham, tais como as celebridades, ainda que essas histórias, ou notícias, se refiram a um crime, o racismo, por exemplo. De fato, Marcondes Filho (2000) ressalta que agora o que interessa ao público é o surpreendente, e não mais o simplesmente informativo. O que se refere, por exemplo, à vida das 
celebridades, especialmente, se associado à violência e ao sofrimento, tende a despertar o interesse de um público ávido por se surpreender.

Dessa forma, são três as principais características da notícia light: a capacidade i) de distração; ii) de espetacularização e iii) de alimentação das conversas (TARRUELLA; GIL, 1997). O que conduz à definição proposta por Dejavite (2007, p. 06) "resumidamente, a notícia light pode ser definida como aquele conteúdo rápido, de fácil entendimento, efêmero, de circulação intensa, que busca divertir o receptor" (grifo da autora), ou seja, atende à demanda da sociedade da informação.

O conceito de jornalismo light remete ao de jornalismo sensacionalista cujo discurso pode ser entendido como um

modo de produção discursivo da informação de atualidade, processado por critérios de intensificação e exagero gráfico, temático, linguístico e semântico, contendo em si valores e elementos desproporcionais, destacados, acrescentados ou subtraídos no contexto de representação ou reprodução de real social (PEDROSO, 2001, p. 52)

Ao descrever o modo sensacionalista de fazer jornalismo, Pedroso (2001) menciona a valorização da emoção em detrimento da informação que sintetiza os outros diversos aspectos elencados pela autora. Agrimani (1995, p. 16) acrescenta que o objetivo é "sensacionalizar aquilo que não é necessariamente sensacional" o que, por sua vez, confere um aspecto negativo, de pouca credibilidade, ao meio que o adota.

Diferentemente da linguagem utilizada nos jornais informativos, o dito jornalismo sério, no discurso sensacionalista ela é coloquial, mas com exageros, gírias e palavrões, uma vez que almeja envolver emocionalmente o leitor com o texto (Agrimani, 1995, p. 16). A linguagem deve ser chocante e impactante, ou, nas palavras do autor, a linguagem editorial sensacionalista é a do clichê (Agrimani, 1995, p. 39). Sendo assim, pode-se dizer que o modus operandi sensacionalista constitui um estilo ou uma estratégia jornalístico-discursiva que tem um objetivo específico, qual seja, manipular as emoções do leitor.

Ao mesmo tempo em que discute a imprensa sensacionalista, a partir da análise do jornal Notícias populares ${ }^{2}$, Agrimani (1995) ressalta que o jornalismo informativo (ou sério) também usa eventualmente essa estratégia em seu discurso. Além disso, aponta o autor, a exploração da violência não é característica específica do jornalismo sensacionalista. De fato, "nos jornais não-sensacionalistas,

\footnotetext{
${ }^{2}$ Vinculado ao Grupo Folha, o jornal Notícias Populares parou de circular em janeiro de 2001. A análise foi feita com textos publicados no mês de agosto de 1990.
} 
há sempre uma carga intensa de violência que não se revela, que não se escancara" (Agrimani, 1995) da mesma forma que no jornalismo sensacionalista. No jornalismo informativo essa violência pode ser observada, por exemplo, no editorial ou no artigo agressivo, na foto impactante.

No discurso do jornal Correio, um jornal que pode ser descrito como um jornal informativo ou sério, foram identificados recursos linguísticos utilizados com o objetivo de explorar a emoção do leitor, ou seja, utilizados mais ao modo sensacionalista para o tratamento concedido ao crime de racismo em suas notícias. Neste trabalho, o foco está especificamente nos modos de operação da intertextualidade e nas formas de representação de atores sociais, considerando as manchetes das notícias que compõem o corpus selecionado.

\section{INTERTEXTUALIDADE E REPRESENTAÇÃO DE ATORES SOCIAIS}

A Análise Crítica do Discurso tem como objetivo central discutir como as relações de poder (GRAMSCI, 1986) se manifestam no discurso para, a partir dessa percepção, desnaturalizar como tais relações podem ser abusivas para uma parte significativa da sociedade. Considerando a relação interna e dialética entre a linguagem e a sociedade, entende-se que questões discursivas são questões sociais e, em contrapartida, questões sociais são também questões discursivas. Sendo assim, é importante a discussão sobre como a mídia online reconfigura determinados discursos, pois muitas vezes as relações abusivas de poder estão escondidas nas entrelinhas do texto.

Neste trabalho, a concepção de discurso adotada é a mesma proposta por Fairclough (2003), segundo a qual discurso pode ser compreendido de dois modos. Primeiro, de modo abstrato como o momento irredutível da vida social; e segundo, de modo concreto como um modo específico de representar a experiência no mundo. Dessa forma, os textos veiculados no jornal Correio estão sendo entendidos como exemplos de um momento irredutível da vida social que, por sua vez, refletem geralmente um discurso mais próximo ao das classes dominantes da sociedade brasileira ou um modo específico de representar a experiência no mundo.

Fairclough $(2003,2008$ [1992]) discute os efeitos e mudanças que podem ser provocados por meio de textos, mudanças nas relações sociais e até mesmo no mundo material. No entanto, afirma o autor, não se pode falar em um padrão regular associado a determinado tipo de texto ou estrutura de texto. Na verdade, os efeitos potenciais de um texto são provenientes também de outros aspectos do contexto, bem como dos objetivos de seu autor. Dessa forma, qualquer recurso linguístico pode ser usado com determinado objetivo; por exemplo, o uso que se faz da intertextualidade nas notícias de 
jornal pode levar a interpretações distintas a depender não só do objetivo do autor do texto, mas também do sentido construído pelo interlocutor/leitor. E aqui é importante ressaltar que, tanto as vozes citadas, e o modo como são citadas, quanto as vozes que são silenciadas revelam sentidos específicos considerando-se a rede de sentidos articulada em determinado texto.

Textos, enquanto elementos de eventos sociais, podem variar a maneira de revelar sua orientação para a diversidade (FAIRCLOUGH, 2003). O autor identifica cinco possiblidades de cenários: (a) uma abertura para a diferença; (b) uma acentuação da diferença; (c) uma tentativa de resolver ou superar a diferença; (d) um escalonamento da diferença e (e) consenso. Ressalta ainda a possibilidade de um texto combinar mais de um desses cenários de diversas maneiras. Tal orientação para a diversidade remete à dialogicidade nos textos, tal como proposta por Bakhtin (2006 [1929]), para quem textos sempre estabelecem diálogos com outros textos, ou seja, a linguagem é entendida como essencialmente dialógica.

Diante do caráter dialógico da linguagem, pode-se dizer que a intertextualidade constitui uma das formas de expressão dessa dialogicidade ou da orientação para a diversidade. A intertextualidade é a presença explícita de outros textos reais em determinado texto, ou seja, refere-se principalmente às citações. Embora um dos focos deste trabalho esteja na intertextualidade é importante registrar que ela não é a única maneira de se incorporar elementos de outros textos. Fairclough (2003) trata também da pressuposição e da ironia, por meio das quais elementos de outros textos são incorporados sem atribuição a um texto específico.

Em princípio tanto a pressuposição quanto a intertextualidade se referem a conteúdo de fato dito ou escrito em algum outro texto. Mas a verdade é que não se tem garantias dessa veracidade. $\mathrm{O}$ autor do texto pode por engano ou desonestidade atribuir falas a quem não as disse, ou tomar como pressuposto algo só reconhecido como tal em determinado grupo. Dessa forma, é possível naturalizar ideologias de um grupo social, apresentando-as como se fossem comuns a outros grupos também. Dito de outra forma, é a representação de um interesse ou identidade particular como se fossem universais, com o intuito de se alcançar ou manter a hegemonia, o que é em parte uma questão textual (Fairclough, 2003). É o que se pode entender como manipulação discursiva.

Fairclough (2003) ressalta ainda uma importante diferença entre a intertextualidade e a pressuposição. Para o autor, a intertextualidade amplia a diferença já que traz outras vozes para o texto de modo explícito, por meio dos discursos direto ou indireto, ao passo que a pressuposição reduz a diversidade ao assumir uma base comum. 
Especificamente sobre a intertextualidade, Fairclough (2003) propõe que se investigue que vozes são incluídas no texto, quais são excluídas e, ainda, qual o significado de tais ausências. Além desses questionamentos, é importante que se analise também como determinadas vozes são incluídas no texto, a partir, por exemplo, do uso dos verbos introdutores de opinião, além de como os donos das vozes, os atores sociais, são representados ${ }^{3}$ no texto.

Fairclough (2003) aponta as seguintes formas de relatar outra voz em um texto: (a) relato direto ou citação; (b) relato indireto ou resumo; (c) relato indireto livre, entre o direto e o indireto; e (d) relato narrativo do ato de fala, sem referência ao seu conteúdo. E, ainda segundo Fairclough (2003), é o gênero que determina o modo de distribuição entre a voz do autor do texto e as vozes relatadas de modo direto ou indireto, o que denomino como gerenciamento de vozes (Oliveira, 2014).

A intertextualidade é também uma questão de recontextualização. De acordo com Fairclough (2003) e Chouliaraki e Fairclough (1999), a recontextualização pode ser entendida como o uso de elementos de uma prática social em outra, um movimento de um contexto para outro. Por exemplo, no caso da intertextualidade, o uso de citações de uma entrevista na composição de uma reportagem, com as adaptações adequadas aos objetivos da reportagem, a saber, qual verbo introdutor de opinião deve ser usado, se se trata de uma citação direta ou relato indireto, entre outros aspectos que podem ser investigados. Fairclough (2003) destaca ainda duas questões a serem resolvidas no caso da intertextualidade: (a) a relação entre o relato e o original e (b) a relação ente o relato e o resto do texto no qual ele ocorre.

Considerando-se que a intertextualidade é uma questão de recontextualização, pode-se dizer que a representação de atores sociais constitui aspecto importante, além de fortemente relacionado à intertextualidade, uma vez que as vozes recontextualizadas pertencem a determinadas pessoas ou instituições, ou seja, a determinados atores sociais. Dessa forma, a maneira como atores sociais são representados em determinado discurso também contribui para a compreensão sobre como a recontextualização interfere na construção de sentidos nesse discurso.

Van Leeuwen (2008 [1996]) apresenta um leque de categorias analíticas específicas que estabelecem uma relação entre fenômenos linguísticos e fenômenos sociais e permitem refletir sobre como eventos e atores sociais são representados em determinado discurso e o que esse modo de representação significa naquele discurso.

\footnotetext{
${ }^{3}$ A representação de atores sociais nas notícias sobre racismo do jornal Correio também será analisada neste artigo.
} 
A partir da metafunção ideacional ${ }^{4}$, tal como proposta por Halliday (HALLIDAY; MATTHIESSEN, 2004), van Leeuwen (2008 [1996]) apresenta uma descrição sociossemântica detalhada das maneiras por meio das quais é possível representar um ator social em determinado discurso. Esse sistema parte de duas categorias gerais: a exclusão e a inclusão dos atores no discurso. Neste artigo, o foco recai sobre os atores sociais incluídos, tendo em vista o objetivo de verificar como é construído o ponto de vista veiculado no discurso do jornal Correio sobre o crime de racismo e sobre os atores sociais envolvidos. Os atores sociais são excluídos quando os agentes dos processos descritos não são explicitados e são incluídos quando podem ser personalizados ou impersonalizados; se personalizados, determinados ou indeterminados. Quando determinados, podem ser categorizados quanto à funcionalização ou quanto à identificação. Eles podem ainda ser genericizados ou especificados. Quando especificados, podem ser categorizados por individualização ou por assimilação. Os atores sociais podem ser referidos ainda por meio da avaliação. Além desses, o processo de inclusão dos atores sociais no discurso pode estar relacionado também à análise de papéis ativos e passivos desempenhados por eles no discurso.

No próximo item, mostrarei os resultados da análise de como o crime de racismo é recontextualizado nas notícias do jornal Correio, tendo como foco as categorias analíticas intertextualidade e representação de atores sociais apresentadas acima.

\section{O CRIME DE RACISMO RECONFIGURADO NA PRÁTICA DISCURSIVA DO JORNAL CORREIO}

Em minha investigação sobre a temática do racismo no jornal Correio, encontrei 54 notícias sobre esse crime durante todo o ano de 2016. A busca foi feita por palavras-chave no próprio portal de notícias do jornal na internet. Utilizei duas palavras-chave: racismo e injúria racial, o que se justifica porque no Brasil, em geral, utiliza-se o termo racismo para o crime que legalmente 5 é denominado como injúria racial. Nesse corpus o crime foi identificado como injúria racial em 4 textos.

É importante ressaltar também que o corpus foi composto apenas pelas notícias cuja temática central se refere a algum crime de racismo específico (optei pelo termo racismo para ser coerente com o uso já consagrado). Não selecionei textos nos quais, por exemplo, o entrevistado, o ator Lázaro Ramos, fala de diversos assuntos e, entre eles, sobre o racismo, mas apenas de maneira genérica e não

\footnotetext{
${ }^{4}$ A metafunção ideacional ou experiencial se relaciona com a realidade presente em determinado texto, ela relaciona o texto e o mundo real.

${ }^{5}$ Lei 7.716, de 05 de janeiro de 1989 que define os crimes resultantes de preconceito de raça ou de cor.
} 
sobre um crime específico. Dessa forma, reitero que meu intuito é analisar como o crime de racismo é recontextualizado na mídia online, representada nesta pesquisa pelo portal de notícias do jornal Correio.

$\mathrm{Na}$ primeira leitura dos 54 textos encontrados, chamou a atenção o uso peculiar da intertextualidade, da citação direta ou indireta de vozes diferentes da do autor do texto, bem como as formas de representação dos atores sociais, mais especificamente as vítimas de racismo e também os supostos racistas. Mas antes de me debruçar sobre esses aspectos linguístico-textuais específicos, vou direcionar meu olhar para o lugar onde essas notícias foram publicadas no site do jornal. Em qual seção ou quais seções o crime de racismo aparece? Tal análise permitirá fazer as primeiras observações sobre como a questão do racismo é tratada no discurso veiculado pelo Correio.

\subsection{A localização da temática}

Das 54 notícias sobre racismo publicadas no Correio em 2016, 22 aparecem na seção Famosos, 9 na seção Brasil, 8 na seção Salvador, 4 na seção Mundo e 2 na seção Bahia. As demais notícias aparecem nas seções: Variedades, Futebol, Olimpíada, Educação, TV, Bazar, Carnaval, Cinema e Esportes; nesses casos, apenas uma notícia foi encontrada em cada uma dessas seções.

E o que essa distribuição significa? Significa que $40 \%$ das notícias sobre o crime de racismo, no ano de 2016, foram publicadas na seção Famosos do jornal Correio, ou seja, o crime de racismo, na maioria dos casos, foi tratado como mais uma curiosidade sobre celebridades. É fato também que a maior parte das notícias sobre racismo se refere a vítimas famosas ou filhos de famosos: atores, cantores, jogadores de futebol, entre outros. Para ser mais precisa, em $61 \%$ das notícias sobre racismo veiculadas no jornal Correio em 2016 as vítimas são pessoas famosas ou seus filhos. Especificamente sobre racismo praticado em Salvador contra pessoas anônimas, encontramos 2 notícias, de um total de 54.

Essas informações são pertinentes porque revelam aspectos importantes sobre a orientação ideológica do jornal Correio. O racismo que merece destaque é aquele sofrido pelos famosos. O racismo cotidiano sofrido por milhares de pessoas anônimas todos os dias no Brasil inteiro não merece o mesmo destaque no discurso de um dos maiores jornais que circulam na capital baiana, Salvador, a cidade considerada a mais negra do Brasil ${ }^{6}$. E o racismo sofrido pelos soteropolitanos também não é

\footnotetext{
${ }^{6}$ https://ww2.ibge.gov.br/home/estatistica/populacao/caracteristicas_raciais/default raciais.shtm
} 
importante nesse discurso. Dessa forma, observa-se uma espetacularização do crime de racismo, uma vez que essa temática emerge nesse discurso majoritariamente relacionada a pessoas famosas e a seus filhos e, como mostrarei adiante, há também aspectos linguístico-textuais que permitem essa leitura.

O objetivo dessa investigação é exatamente compreender como essa espetacularização acontece, considerando-se a intertextualidade e a representação de atores sociais das notícias em tela.

É importante notar também que não foi encontrada nenhuma discussão sobre racismo nas seções de opinião, aquelas que revelam de modo claro os temas que são, de fato, importantes para a instituição jornalística, que revelam sua linha editorial ou ideológica. Durante o ano de 2016 não se dedicou um editorial ou um artigo de opinião a um dos crimes de racismo noticiados no próprio ou em outro jornal/revista. Nem mesmo uma discussão mais genérica sobre a questão do racismo foi encontrada em um gênero jornalístico opinativo do Correio. Nos gêneros opinativos, o racismo emerge apenas de modo tangencial ou secundário.

De acordo com Melo (2003, p. 102), a "valoração dos acontecimentos concretiza-se através dos gêneros opinativos", tais como editorial, artigo de opinião, resenha, coluna. Entre esses, o editorial é o gênero jornalístico por meio do qual a empresa expressa seu ponto de vista oficial sobre os fatos de maior destaque em determinado momento (MELO, 2003). Sendo assim, o editorial se apropria de determinado assunto para redimensioná-lo e recontextualizá-los à luz do ponto de vista da instituição jornalística pela qual será publicado. Os temas abordados nos editoriais podem ser os mais variados, desde que estejam em evidência no momento da publicação do texto e, evidentemente, sejam adequados à linha editorial do veículo no qual são publicados.

A partir dos aspectos destacados por Melo (2003) em relação ao editorial e aos gêneros opinativos jornalísticos em geral, pode-se inferir que para o jornal Correio a temática referente ao racismo não é considerada importante, ou não é relevante, uma vez que não foi considerada fato de maior destaque em determinado momento durante todo o ano de 2016 e também não se adequa a sua linha editorial. Ainda que se trate de um dos jornais de maior circulação da capital mais negra do Brasil, Salvador.

\subsection{Intertextualidade e representação de atores sociais nas manchetes das notícias}

Como já foi dito, nas notícias em tela, a maioria das vítimas de racismo são pessoas famosas ou seus filhos. Essa constatação pode ser demonstrada também por uma análise mais sistemática das manchetes dessas notícias, utilizando como aparato metodológico o sistema sóciosemântico proposto 
por van Leeuwen (2008 [1996]). Para o autor, a forma como atores sociais são representados em textos pode revelar posicionamentos ideológicos em relação a eles, uma vez que podem ser representados por suas vozes ou atividades, suas atividades podem ser destacadas ou obscurecidas e sua representação ou não nos textos pode explicitar julgamentos relativos ao que são ou ao que fazem (van Leeuwen, 2008 [1996]).

A manchete, de acordo com Pedroso (2001), é a mediação dos títulos com o texto; concentrase, pois, na manchete, efeitos discursivos específicos que podem revelar, aos olhos mais atentos, intencionalidades e sentidos ocultos em suas entrelinhas. De fato, já que "o superinvestimento de sentido na manchete a responsabiliza pelo consumo das representações construídas pelo enunciador" (Pedroso, 2001, p. 80). Se a publicidade da edição do dia acontecia principalmente pela exposição do mesmo nas bancas de jornais, pode-se dizer que atualmente ela acontece também pela "corrida de olhos” feita na primeira página do jornal disponibilizado na internet. É nesse momento que o leitor decide ler ou não o jornal, seja na banca física, seja online. Dessa forma, pode-se dizer que a manchete se constitui em um dos aspectos centrais do discurso jornalístico, se não, o principal.

Nas manchetes das notícias sobre racismo, observou-se que as vítimas desse crime ocupam um lugar de destaque, uma vez que ocupam principalmente papéis ativos nesse discurso. De um total de 57 representações de vítimas ${ }^{7}, 32$, ou 56\% do total, ocupam papeis ativos nas orações, a saber, Dizente (14 ocorrências): Adélia diz que vai entrar na Justiça por ofensas racistas em redes sociais (26/04), Taís Araújo fala sobre prisão de acusados de ataques racistas na web; Portador (11 ocorrências): Michele Obama é alvo de racismo por prefeita e funcionária: 'macaca de salto' (16/11), Preta Gil é vítima de preconceito na internet e desabafa: 'Covardes' (26/07); e Ator (7 ocorrências): Ludmilla processa Val Marchiori por comentário racista no Carnaval (19/04); Ator Alan Miranda fará campanha nas redes sociais com a filha contra preconceito (06/05).

Esses exemplos evidenciam também que as vítimas de racismo, em geral, são Nominalizadas: Taís Araújo, Michele Obama, Ludmilla. Em contrapartida, os supostos racistas são principalmente Identificados por meio de Classificação (34\% das 32 ocorrências): Justiça autoriza quebra de sigilo dos autores de ofensas raciais contra filha de Bruno Gagliasso (21/11), Justiça libera três presos acusados de racismo contra Taís Araújo (20/03) e também por meio da Funcionalização (28\% das ocorrências): Policial é exonerada após publicar foto com legenda racista nos EUA (28/09), Conselheiro Federal faz

\footnotetext{
${ }^{7}$ No grupo que denomino vítimas, considero também seus pais, por exemplo, no caso da filha dos atores Bruno Gagliasso e Giovanna Ewbank.
} 
post racista sobre goleira da seleção feminina (14/08). Essa comparação mostra que, nesse discurso, o foco não é lançado sobre o suposto racista, mas sobre suas vítimas, especialmente porque se trata, em sua maioria, de celebridades, o que reforça a percepção de que o intuito do jornal é transformar o crime em mais uma curiosidade sobre o mundo das celebridades, ou seja, em mais um espetáculo.

Corrobora para essa percepção também o fato de os supostos racistas terem sido Nominalizados em apenas 4 ocorrências: Sílvio Santos é acusado de racismo após comentário sobre cabelo de criança (05/09), BBB16: depois de declaração polêmica, internautas acusam Munik de racismo (28/03), Ludmilla pede indenização de R\$ 300 mil a Val Marchiori por injúria racial (21/07) e Ludmilla processa Val Marchiori por comentário racista no Carnaval (19/04). Observe-se que os supostos racistas Nominalizados são também celebridades, ou seja, são também pessoas capazes de atrair a atenção do leitor que se interessa pela vida dos famosos. Além de demonstrar uma tentativa de proteção à maioria dos acusados ao não lhes identificar nominalmente, também reforça a percepção de uma espetacularização de um crime por meio de recursos linguístico-textuais.

Observou-se ainda que, além de, em geral, não serem referidos pelo nome, os supostos racistas aparecem principalmente em posição ativa, tal como acontece com suas vítimas, embora em número menor. De um total de 36 ocorrências, 23, ou 64\%, ocorrem em posição ativa, sendo os papeis mais recorrentes, Portador (9 ocorrências): Adolescente negra é responsável por ataques racistas contra filha de Gagliasso (21/12) e Mulher é presa por prática de racismo em supermercado do Rio de Janeiro; Ator (9 ocorrências): Pedagoga paga R\$ 500 e é liberada após ataque racista: 'preto é nojento, é lixo' (01/09) e Pai veste menino de macaco e causa polêmica nas redes sociais: 'Racistas" (09/02); Dizente (5 ocorrências): Professora chama aluno negro de macaco durante briga em escola no Rio (21/09) e Oscar: "Talvez os negros não merecessem estar na lista final", diz atriz inglesa (22/01).

As formas de representar atores sociais nas notícias sobre racismo permitem inferir que o objetivo do jornal Correio talvez não seja a denúncia de um crime, mas seduzir seus leitores utilizando como atrativo eventos relacionados a famosos, independentemente de sua natureza. Dito de outra forma, pode-se dizer que o jornalismo praticado pelo Correio, nos casos em que trata de racismo, apresenta traços do denominado jornalismo light ou de INFOtenimento. Essa afirmação é reforçada pela ausência significativa de notícias sobre o mesmo crime cometido contra pessoas anônimas. É como se o jornal se apresentasse como uma continuidade dos programas de TV nos quais tais celebridades atuam, ao mesmo tempo em que transmite a ideia de que, de modo geral, não há racismo no cotidiano dos negros anônimos que vivem em Salvador ou em outras cidades do país. 
Nas manchetes das notícias sobre racismo do jornal Correio, em geral, o tema ${ }^{8}$ é composto pelas vítimas que, como já foi dito, em sua maioria (43\%), são famosos ou seus filhos, como em Cantora Zendaya é vítima de racismo em supermercado nos EUA (21/09); Taís Araújo fala sobre prisão de acusados de ataques racistas na web (16/03) e Filha de ator Alan Miranda é vítima de injúria racial na escola (05/05). Os supostos racistas também aparecem na posição de tema da manchete, mas em número menor (19\%): Mulher é presa por prática de racismo em supermercado do Rio de Janeiro (30/05); Baiano é preso por racismo contra atriz Taís Araújo e Maju em Brumado e Professora chama aluno negro de macaco durante briga em escola no Rio (21/09).

Esses exemplos demonstram que o maior destaque no discurso do jornal Correio recai sobre as vítimas de racismo, uma vez que elas aparecem majoritariamente na posição de tema das manchetes. No entanto, essas vítimas são principalmente pessoas famosas ou seus filhos, o que acaba por escamotear o racismo cotidiano, aquele que acontece frequentemente contra pessoas anônimas. Dito de outra forma, o foco do discurso do Correio, nas notícias sobre racismo, está em publicizar o racismo contra celebridades, o que também conduz à percepção de uma espetacularização do crime.

Nas manchetes destaca-se também o recurso à intertextualidade, a ocorrência de vozes citadas, direta ou indiretamente, de vítimas e de supostos racistas. 'Isso é crime e quem fez tem que pagar', diz Gagliasso sobre filha (25/12); Preta Gil presta depoimento na polícia sobre ataques racistas: 'Preocupada e triste' (26/07); Gerente de lanchonete chamado de 'macaco' denuncia cliente no Rio de Janeiro (05/09) e Oscar: 'Talvez os negros não merecessem estar na lista final', diz atriz inglesa (22/01). A presença recorrente de outras vozes nas manchetes das notícias, antecipa o que foi constatado na leitura preliminar dos textos: as notícias são narradas, principalmente, pelos envolvidos e, dessa forma, a voz do jornal fica em um plano secundário quando a temática da notícia é o crime de racismo.

Para além da simples presença da voz dos supostos racistas, é importante considerar o conteúdo representado, já que apenas em duas manchetes há a ocorrência de uma tentativa de defesa por parte dos acusados: 'Assumi, mas não foi pra ela', diz suspeito por ataques racistas a Ludmilla (24/05) e Baiano preso por ofensas contra Taís Araújo e Maju diz que teve sua conta hackeada (17/03); nas demais ocorrências de representação das vozes dos acusados, 8 de um total de 10, o conteúdo representado é exatamente a ofensa proferida contra as vítimas: BaianaSystem é vítima de racismo na

\footnotetext{
${ }^{8} \mathrm{Na}$ estrutura temática de uma oração, o tema é o ponto de partida da mensagem e, por isso, orienta a oração em seu contexto.
} 
internet durante show: 'Macacos' (30/12) e Professora que chamou aluno de 'macaco' é afastada de escola no Rio (22/09). Qual seria a intencionalidade da utilização desse recurso linguístico, a intertextualidade, ao veicular especificamente esse conteúdo ofensivo?

Como já foi dito, assim como na imprensa sensacionalista, no jornalismo sério também se registra a exploração da violência como forma de atrair o leitor. A diferença é que no jornalismo sério, como o Correio, a violência é, aparentemente, menos evidente uma vez que já está naturalizada pela sociedade, o que não a torna menos nociva se considerarmos que o racismo é um crime caracterizado por uma violência também psicológica. A inferiorização do negro no passado pela ciência ecoa nos dias atuais e se reflete em atitudes racistas e na exploração de ofensas racistas pela mídia, como se pode observar no discurso do jornal Correio. Se não o intuito de explorar essa violência para atrair o leitor, qual o intuito de se reproduzir ofensas racistas nas manchetes do jornal?

\section{CONSIDERAÇÕES FINAIS}

Retomando o objetivo deste trabalho, procurei analisar o discurso do jornal baiano Correio no que se refere ao tratamento dispensado às notícias que tratavam do crime de racismo e que foram publicadas no ano de 2016. Para tanto, recorri às estratégias textual-discursivas intertextualidade e representação de atores sociais com intuito de investigar como esse crime é reconfigurado nesse discurso.

As análises mostraram que a maioria das notícias sobre o crime de racismo é publicada em colunas de variedades, sendo a mais recorrente a coluna Famosos, e que as vítimas dos crimes noticiados são principalmente celebridades ou seus filhos, o que revela uma primeira pista para a demonstração de como o jornal transforma um crime em mais um espetáculo a ser consumido pelo público leitor. O que acontece por meio da prática de um jornalismo de INFOtenimento (CASTELLS, 1999; DEJAVITE, 2007) ou da notícia light (DEJAVITE, 2007), ou seja, trata-se de um jornalismo que tem por objetivo muito mais seduzir do que informar o leitor e apresenta também elementos do jornalismo sensacionalista (AGRIMANI, 1995), ainda que o jornal Correio seja, em geral, considerado sério.

Além da localização das notícias sobre racismo, a representação dos principais atores sociais nessas notícias, a saber, os supostos racistas e suas vítimas, também revela uma tendência de omitir o nome dos acusados e, em contrapartida, a Nomeação explícita das vítimas. Da mesma forma, usa-se os 
nomes das celebridades para tornar o crime de racismo mais um espetáculo a ser consumido pela sociedade contemporânea.

Observei também que, de acordo com o discurso do jornal Correio, o crime de racismo acontece fundamentalmente contra celebridades e seus filhos, ou seja, cidadãos negros anônimos, em geral, não são vítimas de racismo em seu cotidiano.

A despeito de a intertextualidade se constituir como uma abertura para a diferença em determinado discurso, tendo em vista os cenários elencados por Fairclough (2003), fato é que seu conteúdo pode refletir também o ponto de vista, a ideologia do autor do texto e, por extensão, do jornal Correio. De fato, todas as escolhas feitas para a construção de determinado texto tem certas intenções, que podem ser mais ou menos explícitas para o interlocutor. E, a partir da análise feita nesse discurso, pode-se dizer que reproduzir ofensas racistas nas manchetes das notícias permite perceber uma ideologia que defende a superioridade da raça branca em relação à negra, considerando-se raça do ponto de vista social. Volto, pois, a questionar, se não o intuito de explorar essa violência como um espetáculo para atrair o leitor, e assim reforçar uma suposta inferioridade dos negros, qual o intuito de se reproduzir ofensas racistas nas manchetes do jornal?

\section{REFERÊNCIAS BIBLIOGRÁFICAS}

AGRIMANI, D. Espreme que sai sangue: um estudo do sensacionalismo na imprensa. São Paulo: Summus, 1995.

BAKHTIN, M. Marxismo e filosofia da linguagem: problemas fundamentais do método sociológico na ciência da linguagem. Tradução Michel Lahud; Yara Frateschi Vieira. São Paulo: Hucitec, 2006 [1929].

BUCCI, E. Sobre ética e imprensa. São Paulo: Companhia das Letras, 2000.

CASTELLS, M. A sociedade em rede. Tradução Roneide Venancio Majer. São Paulo: Paz e Terra, 2005.

DEBORD, G. A sociedade do espetáculo: comentários sobre a sociedade do espetáculo. Tradução Estela dos Santos Abreu. Rio de Janeiro: Contraponto, 2017 [1992].

DEJAVITE, F. A. A notícia light e o jornalismo de infotenimento. In: XXX Congresso Brasileiro de Ciências da Comunicação, 2007, Santos. Anais do Intercom, São Paulo: Intercom, 2007.

FAIRCLOUGH, N. Analysing discourse: textual analysis for social research. Routledge: London, 2003. 
FAIRCLOUGH, N. Discurso e mudança social. Brasília: Ed. UnB, 2008 [1992].

GRAMSCI, A. Concepção dialética da história. Tradução Carlos Nelson Coutinho. Rio de Janeiro: Civilização Brasileira, 1986.

HABERMAS, J. Mudança estrutural da esfera pública: investigações quanto a uma categoria da sociedade burguesa. Tradução Flávio R. Kothe. Rio de Janeiro: Tempo Brasileiro, 2003 [1962].

HALLIDAY, M. A. K.; MATTHIESSEN, C. M. I. M. An introduction to functional grammar. London: Hodder Education, 2004.

MARCONDES FILHO, C. A saga dos cães perdidos. São Paulo: Hacker, 2000.

MELO, J. M. de. Jornalismo opinativo. Campos do Jordão: Mantiqueira, 2003.

OLIVEIRA, D. de. Gerenciamento de vozes no discurso midiático: Caros Amigos X ÉPOCA. Cadernos de Linguagem e Sociedade, Brasília, v.15, n.1, p. 84-100, 2014.

PEDROSO, R. N. A construção do discurso de sedução em um jornal sensacionalista. São Paulo: Annablume, 2001.

TARRUELLA, R. M.; GIL, J. G-L. Noticias frente a hechos: entender la realidade después de ler los periódicos. Barcelona: CIMS, 1997.

VAN LEEUWEN, T. Discourse and practice. New tools for critical discourse analysis. Oxford: University Press, 2008. 